\title{
Posttraumatic stress symptoms in women with gynaecologic pathology: the role of temperament, self-esteem and mental health
}

\author{
Wtodzimierz Oniszczenko ${ }^{1 \cdot A, C, D, E, F, G}$, foanna Szulc ${ }^{2 \cdot A, D, E, F}$, Marek Bulsa ${ }^{3 \cdot B, D, E, F}$, \\ Dariusz Żebiełowicz $z^{3 \cdot B, D, E, F}$ \\ 1: Faculty of Psychology, University of Warsaw, Warsaw, Poland \\ 2: Institute of Psychology, Kazimierz Wielki University, Bydgoszcz, Poland \\ 3: Department of Gynaecology and Obstetrics, Hospital Medical Centre, Goleniów, Poland
}

BACKGROUND

Women with gynaecological pathology are affected by diseases associated with their femininity, attractiveness and fertility. Diseases like these can potentially be sources of trauma for women. The aim of this cross-sectional study was to investigate temperament traits, self-esteem and mental health dimensions that may contribute to the intensity of trauma in hospitalized women.

\section{PARTICIPANTS AND PROCEDURE}

The study was conducted on 136 women aged from 18 to 60 , hospitalized for a variety of gynaecological diseases. The level of trauma symptoms was assessed with the PTSD-Factorial Version inventory. Temperament traits were assessed with the Formal Characteristics of Behaviour - Temperament Inventory (FCB-TI), self-esteem was measured using the Multidimensional Self-Esteem Inventory, and mental health was diagnosed with the General Health Questionnaire - 28 items.

\section{RESULTS}

Emotional reactivity and anxiety symptoms increase trauma symptom intensity in gynaecological patients, where- as briskness, endurance and lovability as a dimension of self-esteem may serve as protective buffers against intensification of trauma symptoms. Together, emotional reactivity, anxiety symptoms and lovability account for $48 \%$ of the variance of trauma intensity symptoms.

\section{CONCLUSIONS}

Emotional reactivity and anxiety symptoms increase trauma symptom intensity in gynaecological patients, whereas lovability as a dimension of self-esteem (and to a lesser extent briskness and endurance as temperament traits) may serve as protective buffers against intensification of trauma symptoms. The findings may have implications for the social support programmes that may be arranged for gynaecological patients.

\section{KEY WORDS}

trauma; temperament; self-esteem; mental health; gynaecologic diseases

CORRESPONDIng AUthor - Prof. Włodzimierz Oniszczenko, Faculty of Psychology, University of Warsaw, 5-7 Stawki Str., 00-183 Warsaw, Poland, e-mail: wlodek@psych.uw.edu.pl

Authors' Contribution - A: Study design - B: Data collection - C: Statistical analysis - D: Data interpretation .

E: Manuscript preparation · F: Literature search · G: Funds collection

to Cite this ARTICle - Oniszczenko, W., Szulc, J., Bulsa, M., \& Żebiełowicz, D. (2016). Posttraumatic stress symptoms in women with gynaecologic pathology: the role of temperament, self-esteem and mental health. Current Issues

in Personality Psychology, 4(4), 196-205.

RECEIVED 18.03.2016 · REVIEWED 30.05.2016 · ACCEPTED 06.06.2016 · PUBLISHED 09.08.2016 


\section{BACKGROUND}

The aim of our study was to investigate the relationship between temperament traits as measured by the Regulative Theory of Temperament (RTT), self-esteem, mental health and posttraumatic stress symptoms (PTSSs) in women with various gynaecological diseases. Our studies are in line with other authors, who have indicated the presence of posttraumatic stress disorder (PTSD) symptoms following medical illness and treatment, including gynaecological procedures (Green, Neria, \& Gross, 2016; Moye \& Rouse, 2014; Roy-Byrne et al., 2008; Tedstone \& Tarrier, 2003).

The psychological consequences of gynaecological diseases have seldom been the subject of research. Available data indicate, for example, that a hysterectomy may lead to the development of depression (Gandyk, Brenner, Tranmer, \& Van Den Kerkhof, 2011; Khastgir, Studd, \& Catalan, 2000; Leppert, Legro, \& Kjerulff, 2007; Raza, Waqas, \& Jamal, 2015; Yen et al., 2008; see also Darwish, Atlantis, \& Mohamed-Taysir, 2014). This effect can also be seen after a diagnosis of polycystic ovarian syndrome (PCOS) (Cipkala-Gaffin, Talbott, Song, Bromberger, \& Wilson, 2012; Jones, Hall, Lashen, Balen, \& Ledger, 2011). Infertile women with PCOS are also characterized by high levels of anxiety (Deeks, Gibson-Helm, \& Teede, 2010; Livadas et al., 2011; Månsson, Holte, Landin-Wilhelmsen, Dahlgren, Johansson, \& Landén, 2008). In addition, endometriosis and chronic pelvic pain can lead to depressive disorders, anxiety and reduced quality of life (QoL) (Jones, Jenkinson, \& Kennedy, 2004; Petrelluzzi, Garcia, Petta, Grassi-Kassisse, \& Spadari-Bratfisch, 2008; Sepulcri \& Amaral, 2009). Several studies have also noted the negative impact of gynaecological diseases on the sexual satisfaction of women of all ages, decreasing QoL and health-related QoL (Bal, Yilmaz, \& Beji, 2013; Laganà et al., 2005; Lammerink, de Bock, Pras, Reyners, \& Mourits, 2012; Ratner, Erekson, Minkin, \& Foran-Tuller, 2011; Safarinejad, Shafiei, \& Safarinejad, 2013). Recurrent vaginal fungal infections and vulvodynia may cause severe emotional and somatic stress symptoms (Ehrström, Kornfeld, \& Rylander, 2007; Ehrström, Kornfeld, Rylander, \& Bohm-Starke, 2009). Gynaecological disease may also have a negative impact on romantic relationships (Gilbert, Ussher, \& Perz, 2011).

With regard to PTSSs in gynaecological patients, empirical data are not very conclusive and indicate the possibility of the development of weak symptoms of the PTSD in people with depression (Guglietti et al., 2010), and especially with chronic pain (Asmundson, 2014; Phifer et al., 2011). Some researchers speculate that the diagnosis of PTSD in gynaecologic oncology may be inappropriate (Greimel et al., 2013). This point of view is contrary to several reports of PTSD development in different groups of oncological patients
(Gold, Douglas, Thomas, Elliott, Rao, \& Miaskowski, 2012; Gonçalves, Jayson, \& Tarrier, 2011).

Numerous authors suggest that personality traits can play a significant role in the response to trauma. In particular, Jakšić, Brajković, Ivezić, Topić, and Jakovljević (2012) found that neuroticism, harm avoidance, novelty-seeking and self-transcendence, as well as hostility/anger and anxiety, are positively correlated with PTSD. On the other hand, extraversion, conscientiousness, self-directedness and hardiness are negatively correlated with PTSD symptoms. Watson and Naragon-Gainey (2014) in their meta-analysis also emphasized the role of neuroticism in the intensity of PTSSs as well as extraversion as a protective factor against PTSSs.

We based our own study on the Regulative Theory of Temperament (RTT) formulated by Strelau (2008). The traits that make up the RTT (Strelau, 1996) are the following: briskness (BR; the tendency to respond swiftly, maintain a high tempo of activity, switch easily from one behaviour to another and adapt to changes in the environment), perseveration (PE; the tendency to maintain and repeat behaviours after the situation that evoked these behaviours has changed), sensory sensitivity (SS; the capacity to respond to sensory stimuli whose stimulating value is low), emotional reactivity (ER; the tendency to respond intensely to emotogenic stimuli, which manifests itself as high emotional sensitivity and low emotional resistance; that is, a low ability to control emotional reactions in response to strong emotogenic stimuli), endurance (EN; the capacity to respond adequately in situations requiring prolonged or highly stimulating activity and/or in conditions of high external stimulation) and activity (AC; the tendency to engage in behaviours that are themselves highly stimulating or that provide highly stimulating environmental input). These traits are related to individual level of arousal. Their significance is particularly obvious when a person is confronted with stressful events.

It is noteworthy that Kandler, Held, Kroll, Bergeler, Riemann, and Angleitner (2012) showed phenotypic links between RTT and Big Five personality traits (extraversion, agreeableness, openness, conscientiousness and neuroticism) that could be attributed mainly to genetic correlations, especially between ER and $\mathrm{PE}$ and neuroticism and between $\mathrm{BR}, \mathrm{EN}$, and $\mathrm{AC}$ and extraversion. This result suggests that RTT and the Big Five traits mentioned above could play similar roles with respect to posttraumatic stress symptoms (i.e., ER and PE may increase PTSSs, while BR, $\mathrm{EN}$ and $\mathrm{AC}$ may serve as protective factors against PTSSs).

Taking the PTSD theoretical construct and its DSM-IV definition (APA, 1994), we distinguished, using a factor analysis, two basic trauma symptoms: intrusion/arousal (I/A) and avoidance/numbing (A/N). The first symptom involves recurrent thoughts (flash- 
backs) about the traumatic event, which are a source of intense psycho-physiological arousal, and the second symptom involves avoidance of trauma-related stimuli and diminished reactions to these stimuli (Strelau, Zawadzki, Oniszczenko, \& Sobolewski, 2002). The results of our previous studies showed that ER and PE intensified PTSSs in cancer patients (Oniszczenko \& Laskowska, 2014), and in HIV+ individuals (Rzeszutek, Oniszczenko, \& Firląg-Burkacka, 2012). Both traits, ER and PE, are also positively correlated with somatic anxiety in students (Fruehstorfer, Veronie, Cremeans-Smith, \& Newberry, 2012). Three other temperament traits, BR, EN and AC, are usually negatively correlated with the severity of PTSSs, and they likely act as resources that protect individuals against the risk of PTSD (the role of SS is unclear).

It seems that gynaecological diseases, especially those related to the reproductive system and which can therefore lead to infertility, can be viewed and judged by women as having serious consequences for their femininity, attractiveness, fertility and overall life situation (risk of loss of a life partner, a change in self-image, or lower self-esteem). As shown by Ying, Wu, and Loke (2015), infertility may be a major cause of loss of female self-esteem. Low self-esteem is likely to be related to worse health (Marmot, 2003). There is little research addressing the relationship between self-esteem and PTSSs. However, Besser, Weinberg, Zeigler-Hill, and Neria (2014) demonstrated a negative correlation between self-esteem and PTSD symptoms among Jewish Israeli adult female civilians. In an earlier study, Bradley, Schwartz, and Kaslow (2005) found a negative association between self-esteem and PTSD symptoms among low-income African American women with a history of intimate partner violence.

With respect to mental health, Chung et al. (2002), using the General Health Questionnaire (GHQ-28), found a positive correlation between PTSSs and all mental health dimensions (somatic problems, anxiety, social dysfunction and depression) following the dissolution of a dating relationship. Chung, Berger, Jones, and Rudd (2008) observed higher levels of the aforementioned mental health dimensions in older myocardial infarction patients with full PTSD compared with a no-PTSD group (see also Horsham \& Chung, 2013). Taubman-Ben-Ari, Rabinowitz, Feldman, and Vaturi (2001) estimated in a national sample that $80 \%$ of the males and $92 \%$ of the females of primary-care attenders diagnosed with PTSD were distressed according to the GHQ (i.e., had a high level of GHQ dimensions).

The purpose of the present study was to determine the relationship between RTT traits and components of self-esteem and mental health with posttraumatic stress symptoms (PTSSs) measured psychometrically, not clinically, in women with gynaecological diseases. In our study, we assumed that ER and PE as temperament traits and anxiety as a component of mental health would contribute to an increase in the severity of PTSSs measured in gynaecological patients. With regard to self-esteem and the relationship between self-esteem components and PTSSs, we did not formulate formal hypotheses due to the exploratory nature of this part of the research.

\section{PARTICIPANTS AND PROCEDURE}

\section{PARTICIPANTS}

We applied a cross-sectional design in this study. The sample consisted of 136 women aged 18 to 60 years $(M=34.60, S D=9.92)$ treated in the Department of Gynaecology and Obstetrics Hospital Medical Centre in Goleniów (Poland) for at least 6 months for different diseases that can lead to infertility (uterine disorders, sarcomas and polyps, tubal occlusion, ovarian cysts, endometriosis and adnexal inflammation). Among the women, 83 were married (61.00\%) and 52 were unmarried (38.20\%); data on the marital status of one person were not available. Regarding children, 35 women had one child $(25.70 \%), 30$ women had two children $(22.10 \%), 12$ women had three children $(8.80 \%)$ and 8 women had more than three children $(5.90 \%)$. There were 51 women without children (37.50\%). Most women (110, or $80.80 \%)$ lived in a city or village, and 25 women lived in rural areas (18.40\%); there was a lack of data on place of residence for one woman. For 54 of the women (39.70\%), this was their first hospital stay, and for 82 of the women (60.30\%) it was their second. The study was anonymous and participation was voluntary. Participants were not paid. The research project was accepted by the local Ethics Commission at the Faculty of Psychology of the university where this study took place. All procedures followed were in accordance with the Helsinki Declaration of 1975, as revised in 2000. Informed consent was obtained from all patients before they were included in the study.

\section{MEASURES}

The quantitative level of PTSSs was assessed with the self-rating PTSD-Factorial Version (PTSDF) inventory. This questionnaire has two scales (Cronbach's $\alpha$ derived from the present sample of women are in parentheses): intrusion/arousal $(\alpha=.95)$ and avoidance/ numbing $(\alpha=.96)$. Scores on each scale were added to calculate the general intensity of PTSSs: general scale $(\alpha=$.97). The PTSDF has 30 items. Each item is rated on a 4-point scale, where 1 means that a symptom is absent and 4 means that it is always present. The validity of this scale was confirmed by correlating it with 
other clinical constructs and with the civilian version of the Mississippi PTSD Scale (Strelau et al., 2002).

Temperament traits were measured with the FCBTI (Strelau \& Zawadzki, 1995). This questionnaire has 120 items (20 items per scale) in a YES/NO response format. The FCB-TI consists of the following scales (Cronbach's $\alpha$ coefficients derived from the present sample of women are in parentheses): briskness $(\alpha=.85)$, perseveration $(\alpha=.83)$, sensory sensitivity $(\alpha=.88)$, emotional reactivity $(\alpha=.82)$, endurance $(\alpha=.81)$ and activity $(\alpha=.83)$.

Self-esteem dimensions were assessed with the Polish version of the Multidimensional Self-Esteem Inventory (MSEI) by Edward J. O'Brien and Seymour Epstein (1988), with the Polish adaptation by Fecenec (2008). Cronbach's $\alpha$ coefficients for the Polish version derived from the present sample of women are in parentheses. The MSEI measures global self-esteem $(\alpha=.78)$ and has eight components: competence $(\alpha=.85)$, lovability $(\alpha=.85)$, likability $(\alpha=.83)$, personal power $(\alpha=.81)$, self-control $(\alpha=.83)$, moral self-approval $(\alpha=.80)$, body appearance $(\alpha=.86)$ and body functioning $(\alpha=.90)$. The MSEI also includes two unique scales: identity integration, which measures global self-concepts $(\alpha=.75)$, and defensive self-enhancement, which differentiates between 'truly high' and 'defensively high' self-esteem $(\alpha=.70)$.

Mental health was measured with the Polish version of the General Health Questionnaire - 28 items (GHQ-28) by David Goldberg (Goldberg \& Hillier, 1979), with the Polish adaptation by Makowska and Merecz (2001). Cronbach's $\alpha$ coefficients for the Polish version derived from the present sample of women and typical items for each subscale are in parentheses. The GHQ-28 measures somatic $(\alpha=.86)$, anxiety/insomnia $(\alpha=.90)$ and depression symptoms $(\alpha=.92)$, and social dysfunction $(\alpha=.92)$. Higher scores indicate a worse general health status. We used the GHQ-28 to assess the emotional (mental) health of patients studied.

\section{STATISTICAL ANALYSIS}

The statistical analysis was performed with IBM SPSS Statistics 21 (IBM Corp., 2012). Correlations between variables were identified using Pearson product-moment correlation coefficients. The validity of the temperament, self-esteem and mental health dimensions as predictors of PTSS intensity was estimated using hierarchical regression analysis.

\section{RESULTS}

The descriptive characteristics of the sample are shown in Table 1.
The results of the correlation analyses between temperament traits, self-esteem, mental health dimensions and PTSSs in gynaecologic patients are shown in Table 2.

Only ER correlated positively with symptoms of trauma in examined women (correlation coefficients were low to moderate). Three other traits, BR, EN

Table 1

Score range, means and standard deviation for age, posttraumatic stress symptoms, temperament traits, self-esteem, and mental health in women with gynaecologic pathology $(n=136)$

\begin{tabular}{|c|c|c|c|}
\hline Variables & $\begin{array}{l}\text { Score } \\
\text { range }\end{array}$ & $M$ & $S D$ \\
\hline Age & $18-60$ & 34.60 & 9.92 \\
\hline \multicolumn{4}{|l|}{ PTSSs } \\
\hline Intrusion/Arousal & $15-60$ & 39.39 & 9.80 \\
\hline Avoidance/Numbing & $15-60$ & 34.57 & 12.41 \\
\hline General Scale & $30-116$ & 73.96 & 21.09 \\
\hline \multicolumn{4}{|l|}{ FCB-TI } \\
\hline Briskness & $0-20$ & 13.11 & 4.84 \\
\hline Perseveration & $2-20$ & 13.65 & 4.57 \\
\hline Sensory Sensitivity & $0-20$ & 13.33 & 5.14 \\
\hline Emotional Reactivity & $0-20$ & 12.75 & 4.55 \\
\hline Endurance & 0-19 & 7.50 & 4.36 \\
\hline Activity & $0-20$ & 9.40 & 4.80 \\
\hline \multicolumn{4}{|l|}{ MSEI } \\
\hline Global Self-esteem & $11-49$ & 29.59 & 6.57 \\
\hline Competence & $13-49$ & 33.24 & 7.14 \\
\hline Lovability & $13-49$ & 32.79 & 7.70 \\
\hline Likability & $10-47$ & 32.08 & 6.91 \\
\hline Personal Power & $14-46$ & 31.11 & 6.79 \\
\hline Self-control & $10-49$ & 29.79 & 7.50 \\
\hline Moral Self-approval & $17-50$ & 36.19 & 6.77 \\
\hline Body Appearance & $10-47$ & 28.95 & 8.03 \\
\hline Body Functioning & $10-45$ & 28.07 & 8.50 \\
\hline Identity Integration & $12-42$ & 29.49 & 6.50 \\
\hline $\begin{array}{l}\text { Defensive Self-En- } \\
\text { hancement }\end{array}$ & $28-66$ & 47.74 & 8.04 \\
\hline \multicolumn{4}{|l|}{ GHQ-28 } \\
\hline Somatic Symptoms & $1-21$ & 12.15 & 5.09 \\
\hline Anxiety Symptoms & $0-21$ & 12.34 & 5.11 \\
\hline Depression Symptoms & $0-20$ & 4.56 & 4.95 \\
\hline Social Dysfunction & $0-21$ & 11.41 & 4.51 \\
\hline
\end{tabular}


and SS, correlated negatively (correlation coefficients were low to moderate). There was a lack of correlation between PTSSs and PE and AC. All self-esteem components (except defensive self-enhancement) negatively correlated with PTSSs (correlation coefficients were low to moderate). The highest negative correlations were found for symptoms of trauma and lovability, and they were only slightly lower for body appearance.

All correlation coefficients between mental health dimensions and PTSSs in gynaecologic patients were high (except for two correlation coefficients between I/A and somatic symptoms and social dysfunction). The strongest correlation coefficient between mental health and trauma was obtained for the level of anxiety symptoms and trauma symptoms.
Correlation analyses revealed that the level of trauma in women with gynaecological diseases is most positively correlated with ER and most negatively correlated with $\mathrm{BR}$ as temperamental traits. Lovability was the dimension of self-esteem most strongly negatively correlated with PTSSs in the study group. Anxiety symptoms and only slightly lower depression symptoms were two psychological dimensions of mental health that were the most positively correlated with trauma level. In order to determine the extent to which these variables may be predictors of general trauma symptoms, a hierarchical regression analysis was performed. Among the temperamental traits, only ER was selected, because this trait is an important risk factor for the development of trauma and is positively correlated with it.

Table 2

Pearson $r$ correlations between temperament traits, self-esteem, mental health dimensions and posttraumatic stress symptoms in women with gynaecologic pathology $(n=136)$

\begin{tabular}{|c|c|c|c|}
\hline & Intrusion/Arousal & Avoidance/Numbing & General Scale \\
\hline \multicolumn{4}{|l|}{ FCB-TI } \\
\hline Briskness & $-.30^{* *}$ & $-.48^{* *}$ & $-.42^{* *}$ \\
\hline Perseveration & .13 & -.05 & .03 \\
\hline Sensory Sensitivity & $-.17^{*}$ & $-.36^{* *}$ & $-.29^{* *}$ \\
\hline Emotional Reactivity & $.30^{* *}$ & $.24^{* *}$ & $.28^{* *}$ \\
\hline Endurance & $-.30^{* *}$ & $-.25^{* *}$ & $-.29^{* *}$ \\
\hline Activity & -.01 & -.04 & .03 \\
\hline \multicolumn{4}{|l|}{ MSEI } \\
\hline Global Self-esteem & $-.31^{* *}$ & $-.30^{* *}$ & $-.32^{* *}$ \\
\hline Competence & -.16 & $-.28^{* *}$ & $-.24^{* *}$ \\
\hline Lovability & $-.36^{* *}$ & $-.42^{* *}$ & $-.41^{* *}$ \\
\hline Likability & $-.32^{* *}$ & $-.38^{* *}$ & $-.37^{* *}$ \\
\hline Personal Power & $-.21^{*}$ & $-.20^{*}$ & $-.22^{*}$ \\
\hline Self-control & $-.30^{* *}$ & $-.32^{* *}$ & $-.33^{* *}$ \\
\hline Moral Self-approval & $-.19^{*}$ & $-.28^{* *}$ & $-.25^{* *}$ \\
\hline Body Appearance & $-.37^{* *}$ & $-.38^{* *}$ & $-.40^{* *}$ \\
\hline Body Functioning & $-.32^{* *}$ & $-.30^{* *}$ & $-.32^{* *}$ \\
\hline Identity Integration & $-.35^{* *}$ & $-.32^{* *}$ & $-.35^{* *}$ \\
\hline Defensive Self-Enhancement & -.10 & -.14 & -.13 \\
\hline \multicolumn{4}{|l|}{ GHQ-28 } \\
\hline Somatic Symptoms & $.46^{* *}$ & $.52^{* *}$ & $.52^{* *}$ \\
\hline Anxiety Symptoms & $.54^{* *}$ & $.64^{* *}$ & $.63^{* *}$ \\
\hline Depression Symptoms & $.52^{* *}$ & $.58^{* *}$ & $.58^{* *}$ \\
\hline Social Dysfunction & $.43^{* *}$ & $.62^{* *}$ & $.56^{* *}$ \\
\hline
\end{tabular}


Table 3

Hierarchical regression analyses with emotional reactivity, anxiety symptoms and lovability as predictors of posttraumatic stress symptoms in women with gynaecologic pathology $(n=136)$

\begin{tabular}{lccccc}
\hline Model & $F$ & $F \Delta R^{2}$ & $R$ & $R^{2}$ & Predictor \\
\hline Emotional Reactivity & $11.63(\mathrm{a})^{* *}$ & - & .28 & .08 & $\begin{array}{c}\text { Emotional reactivity } \\
+ \text { Anxiety Symptoms }\end{array}$ \\
& $47.71(\mathrm{~b})^{* * *}$ & $77.18^{* * *}$ & .65 & .42 & $\begin{array}{c}\text { Emotional reactivity } \\
\text { Anxiety symptoms }\end{array}$ \\
+ Lovability & $40.91(\mathrm{c})^{* * *}$ & $16.32^{* * *}$ & .69 & .48 & $\begin{array}{c}\text { Emotional reactivity } \\
\text { Anxiety symptoms } \\
\text { Lovability }\end{array}$ \\
\hline
\end{tabular}

Note. (a) $d f=1 / 134$, (b) $d f=2 / 133$, (c) $d f=3 / 132 ;{ }^{*} p<.05 ;{ }^{* *} p<.01 ;{ }^{* * *} p<.001$.

The results of the hierarchical regression analysis are presented in Table 3.

The significant predictors of PTSSs in the study group were: ER ( $8 \%$ of explained variance), anxiety symptoms (34\%) and lovability (6\%). Together these three variables accounted for $48 \%$ of the variance of the explained variable.

\section{DISCUSSION}

The study showed that the various gynaecological diseases may be sources of PTSSs as measured psychometrically, in hospitalized women. The differences in the severity of PTSSs in women were significantly conditioned by personality factors.

Among the temperament traits, an important factor in the development of PTSSs was ER, which was positively correlated with PTSSs. According to the hierarchical regression analysis results, ER explained $8 \%$ of PTSS variance (see Table 3). Protective factors in the development of trauma may be BR, EN and SS, which are negatively correlated with PTSSs. These results are consistent with our previous research results on temperament and PTSSs in different clinical groups (Oniszczenko \& Laskowska, 2014; Rzeszutek et al., 2012). Earlier, we explained the protective role of SS in social situations of HIV+ people (Rzeszutek et al., 2012), especially the strong stigma to which they are subjected. In the case of gynaecological patients, assumptions of external stigma are not reasonable, but we cannot rule out the presence and influence of the self-stigma observed, for example, in people with bipolar disorder and alcohol dependence. The presence of disease and surgical intervention involving female genitals can threaten women's self-esteem and foster a sense that they are less feminine than other women, and therefore in some way marked. As a result, the decline in self-esteem is not conducive to self-protection against the effects of emotional events that have occurred because of the disease.

The various components of self-esteem also showed low or moderate correlations with trauma symptoms, but were all negative. These results are in line with those obtained in other studies (Besser et al., 2014; Bradley et al., 2005). This indicates the protective role that women's self-esteem plays in the experience of trauma accompanying disease; the higher the self-esteem, the less severe the trauma symptoms, and vice versa. A particular role may be played by the component of self-esteem associated with lovability, or the experience of social support and acceptance of relatives. This component (or lack thereof) was most strongly associated with symptoms of trauma in the group of women and explained $6 \%$ of PTSSs (see Table 3). This result suggests that being loved is for women - as gynaecological patients - an essential component of their role as women. For example, Hutti, Armstrong, Myers, and Hall (2015) found that poor quality of the intimate partner relationship after perinatal loss may increase not only the intensity of grief but also posttraumatic stress symptoms. Women who feel accepted, loved and supported by loved ones can draw strength from their relationships and develop symptoms of trauma to a lesser extent. The feeling of not being loved and the lack of social support from loved ones when it is needed, or abandonment by a partner - which, in the case of gynaecological diseases that threaten women's sexual attractiveness is likely - intensifies the symptoms of trauma. A particular role is played by social support from a partner. Brewin, Andrews, and Valentine (2000) demonstrated that lack of social support after the trauma has somewhat stronger effects on PTSSs than pre-trauma factors.

Mental health was also found to be strongly associated with symptoms of trauma. Of particular importance were anxiety/insomnia symptoms that may increase general trauma symptoms as measured by the PTSDF inventory. Somewhat weaker correlations were detected for the other symptoms of mental health (i.e., physical symptoms, depression and social dysfunction). According to the hierarchical regression analysis results (see Table 3), anxiety symptoms explained $34 \%$ of PTSS variance. Other studies have shown the particular importance of anxiety (and 
especially insomnia) for the development of posttraumatic stress symptoms (Elliot, McKinley, Fien, \& Elliot, 2016; Nappi, Drummond, \& Hall, 2012). The relationship between sleep disturbance and PTSSs may be bi-directional. It was shown that exposure to trauma may cause sleep disturbance (Babson \& Feldner, 2010), but insomnia and nightmares are also associated with an increased risk for onset and continuance of PTSD (Wright, Britt, Bliese, Adler, Picchioni, \& Moore, 2011), so they may serve as risk factors for PTSSs. In general, the high positive correlations between GHQ-28 dimensions and PTSSs confirmed in our study among patients with gynaecological pathology are in line with the results of previous studies (Chung et al., 2002; Taubman-Ben-Ari et al., 2001).

Summing up, emotional reactivity and anxiety symptoms increase PTSS intensity in gynaecological patients, whereas lovability as a dimension of self-esteem may serve as a protective factor against intensification of PTSSs. Regression analysis showed that ER, anxiety symptoms and lovability account for $48 \%$ of the variance of trauma symptoms. The result we obtained suggests that the psychological care of women with gynaecologic diseases should focus on protection against the emotional consequences of the diseases. The partners of women, their families and psychologists play important roles in this process.

This study is not without limitations. The sample was relatively small and not very heterogeneous in terms of age and diseases diagnosed. It did not take into account previous traumatic events in participants' lives that could have an impact on PTSS level. The study's cross-sectional design does not allow for inferences about causation and the direction of causality.

\section{CONCLUSIONS}

Gynaecological patients experience PTSSs as shown by self-reported data. Emotional reactivity as the RTT trait and anxiety as a mental health component seem to play crucial roles in increasing PTSSs. Lovability as a self-esteem component seems to be a significant protective factor against the incidence of PTSSs. The findings may have implications for the social support programmes that may be arranged for gynaecological patients and their partners.

\section{ACKNOWLEDGMENTS}

This study was funded by grant no. 1615-01-2011 from the University of Warsaw.

\section{References}

American Psychiatric Association, APA. (1994). Diagnostic and statistical manual of mental disorders
(4 ${ }^{\text {th }}$ ed.). Washington, DC: American Psychiatric Association.

Asmundson, G. (2014). The emotional and physical pains of trauma: Contemporary and innovative approaches for treating co-occurring PTSD in chronic pain. Depression \& Anxiety, 31, 717-720. doi: 10.1002/da.22285

Babson, K. A., \& Feldner, M. T. (2010). Temporal relations between sleep problems and both traumatic event exposure and PTSD: A critical review of the empirical literature. Journal of Anxiety Disorders, 24, 1-15. doi: 10.1016/j.janxdis.2009.08.002.

Bal, M. D., Yilmaz, S. D., \& Beji, N. K. (2013). Sexual health in patients with gynecological cancer: A qualitative study. Sexuality and Disability, 31, 83-92. doi: 10.1007/s11195-012-9263-7

Besser, A., Weinberg, M., Zeigler-Hill, V., \& Neria, Y. (2014). Acute symptoms of posttraumatic stress and dissociative experiences among female Israeli civilians exposed to war: The roles of intrapersonal and interpersonal sources of resilience. Journal of Clinical Psychology, 70, 1227-1239. doi: 10.1002/ jclp.22083

Bradley, R., Schwartz, A. C., \& Kaslow, N. J. (2005). Posttraumatic stress disorder symptoms among low-income, African American women with a history of intimate partner violence and suicidal behaviors: Self-esteem, social support, and religious coping. Journal of Traumatic Stress, 18, 685-696. doi: 10.1002/jts.20077

Brewin, C. R., Andrews, B., \& Valentine, J. D. (2000). Meta-analysis of risk factors for posttraumatic stress disorder in trauma-exposed adults. Journal of Consulting and Clinical Psychology, 68, 748-766. doi: 10.1037/0022-006X.68.5.748

Chung, M. C., Berger, Z., Jones, R., \& Rudd, H. (2008). Posttraumatic stress and co-morbidity following myocardial infarction among older patients: The role of coping. Aging and Mental Health, 12, 124133. doi: 10.1080/13607860701366152

Chung, M. C., Farmer, S., Grant, K., Newton, R., Payne, S., Perry, M., ..., Stone, N. (2002). Self-esteem, personality and posttraumatic stress symptoms following the dissolution of a dating relationship. Stress and Health, 18, 83-90. doi: 10.1002/ smi.929

Cipkala-Gaffin, J., Talbott, E. O., Song, M. K., Bromberger, J., \& Wilson, J. (2012). Associations between psychologic symptoms and life satisfaction in women with polycystic ovary syndrome. Journal of Women's Health, 21, 179-187. doi: 10.1089/ jwh.2010.2541

Darwish, M., Atlantis, E., \& Mohamed-Taysir, T. (2014). Psychological outcomes after hysterectomy for benign conditions: a systematic review and meta-analysis. European Journal of Obstetrics, Gynecology, and Reproductive Biology, 174, 5-19. doi: 10.1016/j.ejogrb.2013.12.017 
Deeks, A. A., Gibson-Helm, M. E., \& Teede, H. J. (2010). Anxiety and depression in polycystic ovary syndrome: a comprehensive investigation. Fertility and Sterility, 7, 2421-2423. doi: 10.1016/j.fertnstert.2009.09.018

Ehrström, S., Kornfeld, D., \& Rylander, E. (2007). Perceived stress in women with recurrent vulvovaginal candidiasis. Journal of Psychosomatic Obstetrics and Gynecology, 28, 169-176. doi: 10.1080/01674820601168176

Ehrström, S., Kornfeld, D., Rylander, E., \& BohmStarke, N. (2009). Chronic stress in women with localised provoked vulvodynia. Journal of Psychosomatic Obstetrics and Gynecology, 30, 73-79. doi: 10.1080/01674820802604359

Elliott, R., McKinley, S., Fien, M., \& Elliott, D. (2016). Posttraumatic stress symptoms in intensive care patients: An exploration of associated factors. $R e^{-}$ habilitation Psychology, 61, 141-150. doi: 10.1037/ rep0000074

Fruehstorfer, D. B., Veronie, L., Cremeans-Smith, J. K., \& Newberry, B. H. (2012). Predicting illness-related outcomes with the FCB-TI trait pairs: Examining the nonadditive effects of FCB-TI perseveration. Journal of Individual Differences, 4, 248-256. doi: 10.1027/1614-0001/a000070

Gandyk, A. D., Brenner, I., Tranmer, J., \& Van Den Kerkhof, E. (2011). Depressive symptoms before and after elective hysterectomy. Journal of Obstetric, Gynecologic, \& Neonatal Nursing, 40, 566-576. doi: 10.1111/j.1552-6909.2011.01278.x

Gilbert, E., Ussher, J. M., \& Perz, J. (2011). Sexuality after gynaecological cancer: A review of the material, intrapsychic, and discursive aspects of treatment on women's sexual-wellbeing. Maturitas, 70, 42-57. doi: 10.1016/j.maturitas.2011.06.013

Gold, J. I., Douglas, M. M. K., Thomas, M. L., Elliott, J. E., Rao, S. M., \& Miaskowski, C. (2012). The relationship between posttraumatic stress disorder, mood states, functional status, and quality of life in oncology outpatients. Journal of Pain and Symptom Management, 44, 520-531. doi: 10.1016/j.jpainsymman.2011.10.014

Goldberg, D. P., \& Hillier, V. F. (1979). A scaled version of the General Health Questionnaire. Psychological Medicine, 9, 139-145.

Gonçalves, V., Jayson, G., \& Tarrier, N. (2011). A longitudinal investigation of posttraumatic stress disorder in patients with ovarian cancer. Journal of Psychosomatic Research, 70, 422-431. doi: 10.1016/j.jpsychores.2010.09.017

Green, T., Neria, Y., \& Gross, R. (2016). Prevalence, detection and correlates of PTSD in the primary care setting: A systematic review. Journal of Clinical Psychology in Medical Settings, 23, 160-180. doi: 10.1007/s10880-016-9449-8

Greimel, E., Dorfer, M., Lambauer, M., Bjelic-Radisic, V., Gramm, S., Lahousen, M., ..., Lang, U.
(2013). Posttraumatic stress disorder in female cancer patients: An inappropriate diagnosis in oncology? Psychotherapy and Psychosomatics, 82, 271-272. doi: 10.1159/000348610

Guglietti, C. L., Rosen, B., Murphy, K. J., Laframboise, S., Dodge, J., Ferguson, S., ..., Ritvo, P. (2010). Prevalence and predictors of posttraumatic stress in women undergoing an ovarian cancer investigation. Psychological Services, 7, 266-274. doi: 10.1037/a0020338

Horsham, S., \& Chung, M. C. (2013). Investigation of the relationship between trauma and pain catastrophising: The roles of emotional processing and altered self-capacity. Psychiatry Research, 208, 274-284. doi: 10.1016/j.psychres.2012.11.031

Hutti, M. H., Armstrong, D. S., Myers, J. A., \& Hall, L. A. (2015). Grief intensity, psychological well-being, and the intimate partner relationship in the subsequent pregnancy after a perinatal loss. Journal of Obstetric, Gynecologic, \& Neonatal Nursing, 44, 42-50. doi: 10.1111/1552-6909.12539

IBM Corp. (2012). IBM SPSS Statistics 21 core system user's guide. Somers, NY: IBM Corp.

Jakšić, N., Brajković, L., Ivezić, E., Topić, R., \& Jakovljević, M. (2012). The role of personality traits in posttraumatic stress disorder (PTSD). Psychiatria Danubina, 24, 256-266.

Jones, G., Jenkinson, C., \& Kennedy S. (2004). The impact of endometriosis upon quality of life: A qualitative analysis. Journal of Psychosomatic Obstetrics and Gynecology, 25, 123-133. doi: 10.1080/01674820400002279

Jones, G. L., Hall, J. M., Lashen, H. L., Balen, A. H., \& Ledger, W. L. (2011). Health-related quality of life among adolescents with polycystic ovary syndrome. Journal of Obstetric, Gynecologic, \& Neonatal Nursing, 40, 577-588. doi: 10.1111/j.15526909.2011.01279.x

Kandler, C., Held, L., Kroll, C., Bergeler, A., Riemann, R., \& Angleitner, A. (2012). Genetic links between temperamental traits of the Regulative Theory of Temperament and the Big Five. Journal of Individual Differences, 33, 197-204. doi: 10.1027/16140001/a000068

Khastgir, G., Studd, J. W., \& Catalan, J. (2000). The psychological outcome of hysterectomy. Gynecological Endocrinology, 14, 132-141. doi: 10.3109/09513590009167672

Laganà, L., Classen, C., Caldwell, R., McGarvey, E. L., Baum, L. D., Cheasty, E., ..., Koopman, C. (2005). Sexual difficulties of patients with gynecological cancer. Professional Psychology: Research and Practice, 36, 391-399. doi: 10.1037/0735-7028.36.4.391

Lammerink, E. A. G., de Bock, G. H., Pras, E., Reyners, A. K. L., \& Mourits, M. J. E. (2012). Sexual functioning of cervical cancer survivors: A review with a female perspective. Maturitas, 72, 296304. doi: 10.1016/j.maturitas.2012.05.006 
Leppert, P. C., Legro, R. S., \& Kjerulff, K. H. (2007). Hysterectomy and loss of fertility: Implications for women's mental health. Journal of Psychosomatic Research, 63, 269-274. doi: 10.1016/j.jpsychores.2007.03.018

Livadas, S., Chaskou, S., Kandaraki, A. A., Skourletos, G., Economou, F., Christou, M., ..., DiamantiKandarakis, E. (2011). Anxiety is associated with hormonal and metabolic profile in women with polycystic ovarian syndrome. Clinical Endocrinology, 75, 698-703. doi: 10.1111/j.13652265.2011.04122.x

Månsson, M., Holte, J., Landin-Wilhelmsen, K., Dahlgren, E., Johansson, A., \& Landén, M. (2008). Women with polycystic ovary syndrome are often depressed or anxious - a case control study. Psychoneuroendocrinology, 33, 1132-1138. doi: 10.1016/j.psyneuen.2008.06.003

Marmot, M. (2003). Self-esteem and health: Autonomy, self-esteem, and health are linked together. BMJ: British Medical Journal, 327, 574-575. doi: 10.1136/bmj.327.7415.574

Moye, J., \& Rouse, S. (2014). Posttraumatic stress in older adults: When medical diagnoses or treatments cause traumatic stress. Clinics in Geriatric Medicine, 30, 577-580. doi: 10.1016/j.cger

Nappi, C. M., Drummond, S., \& Hall, J. M. H. (2012). Treating nightmares and insomnia in posttraumatic stress disorder: A review of current evidence. Neuropharmacology, 62, 576-585. doi: 10.1016/j.neuropharm.2011.02.029.

O’Brien, E. J., \& Epstein, S. (1988). MSEI: The Multidimensional Self-esteem Inventory ( $2^{\text {nd }}$ ed.). Odessa, FL: Psychological Assessment Resources, Inc.

Oniszczenko, W., \& Laskowska, A. (2014). Emotional reactivity, coping style and cancer trauma symptoms. Archives of Medical Science, 1, 110-116. doi: 10.5114/aoms.2013.33069

Petrelluzzi, K. F. S., Garcia, M. C., Petta, C. A., GrassiKassisse, D. M., \& Spadari-Bratfisch, R. C. (2008). Salivary cortisol concentrations, stress and quality of life in women with endometriosis and chronic pelvic pain. Stress: The International Journal on the Biology of Stress, 5, 390-397. doi: 10.1080/10253890701840610

Phifer, J., Skelton, K., Weiss, T., Schwartz, A. C., Wingo, A., Gillespie, C. F., ..., Ressler, K. J. (2011). Pain symptomatology and pain medication use in civilian PTSD. Pain, 152, 2233-2240. doi: 10.1016/j. pain.2011.04.019

Ratner, E. S., Erekson, E. A., Minkin, M. J., \& Foran-Tuller, K. A. (2011). Sexual satisfaction in the elderly female population: A special focus on women with gynecologic pathology. Maturitas, 70, 210-215. doi: 10.1016/j.maturitas.2011.07.015

Raza, N., Waqas, A., \& Jamal, M. (2015). Post-operative anxiety, depression and psychiatric support in patients undergoing hysterectomy: A cross sectional survey. The Journal of the Pakistan Medical Association, 65, 443-445.

Roy-Byrne, P. P., Davidson, K. W., Kessler, R. C., Asmundson, G. J. G., Goodwin, R. D., Kubzansky, L., ..., Stein, M. B. (2008). Anxiety disorders and comorbid medical illness. General Hospital Psychiatry, 30, 208-225. doi: 10.1016/j.genhosppsych.2007.12.006

Rzeszutek, M., Oniszczenko, W., \& Firląg-Burkacka, E. (2012). Temperament traits, coping style and trauma symptoms in HIV+ men and women. AIDS Care: Psychological and Socio-medical Aspects of AIDS/HIV, 24, 1150-1154. doi: 10.1080/09540121.2012.687819

Safarinejad, M. R., Shafiei, N., \& Safarinejad, S. (2013). Quality of life and sexual functioning in young women with early-stage breast cancer 1 year after lumpectomy. Psycho-Oncology, 22, 1242-1248. doi: 10.1002/pon.3130

Sepulcri, R., \& Amaral, V. (2009). Depressive symptoms, anxiety, and quality of life in women with pelvic endometriosis. European Journal of Obstetrics \& Gynecology and Reproductive Biology, 142, 53-56. doi: 10.1016/j.ejogrb.2008.09.003

Strelau, J. (1996). The regulative theory of temperament: Current status. Personality and Individual Differences, 20, 131-142. doi: 10.1016/01918869(95)00159-X

Strelau, J. (2008). Temperament as a regulator of behavior: After fifty years of research. New York: Eliot Werner Publications, Inc.

Strelau, J., \& Zawadzki, B. (1995). The formal characteristics of Behavior-Temperament Inventory (FCB-TI): Validity studies. European Journal of Personality, 9, 207-229. doi: 10.1002/per.2410090304

Strelau, J., Zawadzki, B., Oniszczenko, W., \& Sobolewski, A. (2002). Kwestionariusz PTSD - wersja czynnikowa (PTSDC). Konstrukcja narzędzia do diagnozy głównych wymiarów zespołu stresu pourazowego [The factorial version of the PTSD Inventory (PTSD-F): The development of a questionnaire aimed at assessing basic dimensions of posttraumatic stress disorder]. Przegląd Psychologiczny, 45, 149-176.

Taubman-Ben-Ari, O., Rabinowitz, J., Feldman, D., \& Vaturi, R. (2001). Post-traumatic stress disorder in primary-care settings: prevalence and physicians' detection. Psychological Medicine, 31, 555560. doi: 10.1017/S0033291701003658

Tedstone, J., \& Tarrier, N. (2003). Posttraumatic stress disorder following medical illness and treatment. Clinical Psychology Review, 23, 409-448. doi: 10.1016/S0272-7358(03)00031-X

Yen, J. Y., Chen, Y. H., Long, C. Y., Chang, Y., Yen, C.F., Chen, C.C., ..., Ko, C. H. (2008). Risk factors for major depressive disorder and the psychological 
impact of hysterectomy: a prospective investigation. Psychosomatics, 49, 137-142. doi: 10.1176/ appi.psy.49.2.137

Ying, L. Y., Wu, L. H., \& Loke, A. Y. (2015). Gender differences in experiences with and adjustments to infertility: A literature review. International Journal of Nursing Studies, 52, 1640-1652. doi: 10.1016/j.ijnurstu.2015.05.004

Watson, D., \& Naragon-Gainey, K. (2014). Personality, emotions, and the emotional disorders. Clinical Psychological Science, 2, 422-442.

Wright, K. M., Britt, T. W., Bliese, P. D., Adler, A. B., Picchioni, D., \& Moore, D. (2011). Insomnia as predictor versus outcome of PTSD and depression among Iraq combat veterans. Journal of Clinical Psychology, 67, 1240-1258. doi: 10.1002/jclp.20845 